\title{
HVDC grid control system based on autonomous converter control
}

Link to publication record in Manchester Research Explorer

\section{Citation for published version (APA):}

Barnes, M., Beddard, A., Barker, C., \& Adamczyk, A. (2016). HVDC grid control system based on autonomous converter control. In IET Power Electronics, Machines and Drives Conf, April 2016, Glasgow

\section{Published in:}

IET Power Electronics, Machines and Drives Conf, April 2016, Glasgow

\section{Citing this paper}

Please note that where the full-text provided on Manchester Research Explorer is the Author Accepted Manuscript or Proof version this may differ from the final Published version. If citing, it is advised that you check and use the publisher's definitive version.

\section{General rights}

Copyright and moral rights for the publications made accessible in the Research Explorer are retained by the authors and/or other copyright owners and it is a condition of accessing publications that users recognise and abide by the legal requirements associated with these rights.

\section{Takedown policy}

If you believe that this document breaches copyright please refer to the University of Manchester's Takedown Procedures [http://man.ac.uk/04Y6Bo] or contact uml.scholarlycommunications@manchester.ac.uk providing relevant details, so we can investigate your claim.

\section{OPEN ACCESS}




\title{
HVDC Grid Control System Based on Autonomous Converter Control
}

\author{
A. Beddard*, A. Adamczyk ${ }^{\dagger}$, M. Barnes* and C. Barker ${ }^{\dagger}$ \\ *Power Conversion Group, The University of Manchester, UK, ${ }^{\dagger}$ GE Grid Solutions, Stafford, UK, \\ mike.barnes@manchester.ac.uk; andrzej.adamczyk@ge.com
}

Keywords: HVDC, Control, Droop, DC grid, ACC.

\begin{abstract}
In this paper, the main layers of a HVDC control architecture based on autonomous converter control have been implemented and a range of tests have been conducted to assess the system's steady-state and transient performance. The simulation results show that the control system is able to accurately control DC power flow in steady-state and to maintain grid stability for fast transient events without exceeding the dynamic operating limits.
\end{abstract}

\section{Introduction}

There have been a number of proposals to interconnect offshore generation to a common Voltage Source Converter (VSC) High Voltage Direct Current (HVDC) Multi-Terminal (MT) system, such as the European Super Grid. The connection of offshore generation to a common DC grid has the potential to reduce the volume of assets installed offshore and to improve operational flexibility when compared with more conventional point-to-point VSC-HVDC systems. The regulation of the DC link voltage for a MTDC system is however more complex than in a point-to-point system.

Droop control is generally seen as the preferred MTDC control method as it enables more than one converter to participate in the regulation of the DC voltage simultaneously. Autonomous Converter Control (ACC), which was originally proposed by Alstom Grid [1, 2], is seen as one of the leading forms of droop control for MTDC systems. The work which has been conducted thus far has mainly focused on the key control principles operating under normal conditions. The objective of this paper is to further develop and verify the DC grid control concepts by implementing the supplementary control layers, such as the DC Power Flow Solver (PFS) and converter control, and by investigating the system's performance when the DC grid is working near the limit of its operating frame.

\section{Grid Control Architecture}

A simplified diagram of an example HVDC grid control architecture is shown in Figure 1. The HVDC grid could be connected to one or more AC systems, which may be a mixture of traditional onshore AC networks, windfarm power plants and passive loads. The Energy Management System's
(EMS) key function is to determine the DC power $\left(\mathrm{P}_{\mathrm{dc}} *\right)$ orders for each VSC. In order to do this an offshore energy market would probably be necessary. The EMS could also provide additional services such as AC frequency regulation at an extra cost.

The droop gain $\left(\mathrm{K}_{\mathrm{droop}}\right)$ for each converter, which would be set by the EMS, affects how much the power of that converter changes due to a transient event. Some AC system operators may wish to pay to have a droop gain which results in minimal power variation, while other system operators could be compensated for being more flexible.

The main function of the Power Flow Solver (PFS) is to calculate the target $\mathrm{DC}$ voltage $\left(\mathrm{V}_{\mathrm{dc}}{ }^{*}\right)$ for each node, in order to obtain the target DC node powers without exceeding the system's nominal operating limits. The PFS sends the DC voltage order, DC power order and droop gain setting to each VSC control system. The VSC control systems then manipulate their $\mathrm{AC}$ converter voltage references $\left(\mathrm{V}_{\mathrm{ac}}{ }^{*}\right)$ to achieve the target $\mathrm{DC}$ voltage and local reactive power order $\left(Q^{*}\right)$.

The implementation of the EMS is predominantly a policy issue rather than a technical one. This paper therefore focuses on the implementation of the other control layers.

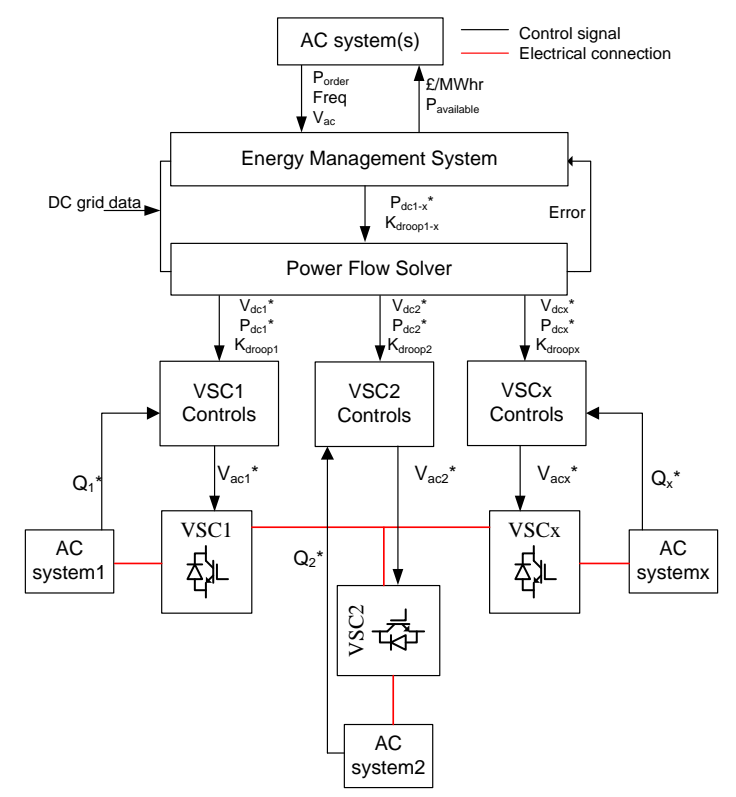

Figure 1: Simplified example of a DC grid control architecture 


\section{NAWC Model}

For this work a model has been developed in PSCAD which is based on the DC configuration of the Northern section of the Atlantic Wind Connection (NAWC), as shown in Figure 2 [3]. The reader should be aware that the DC configuration of this system is based on publicly available information and that no attempt has been made to model the New York/New Jersey power systems.

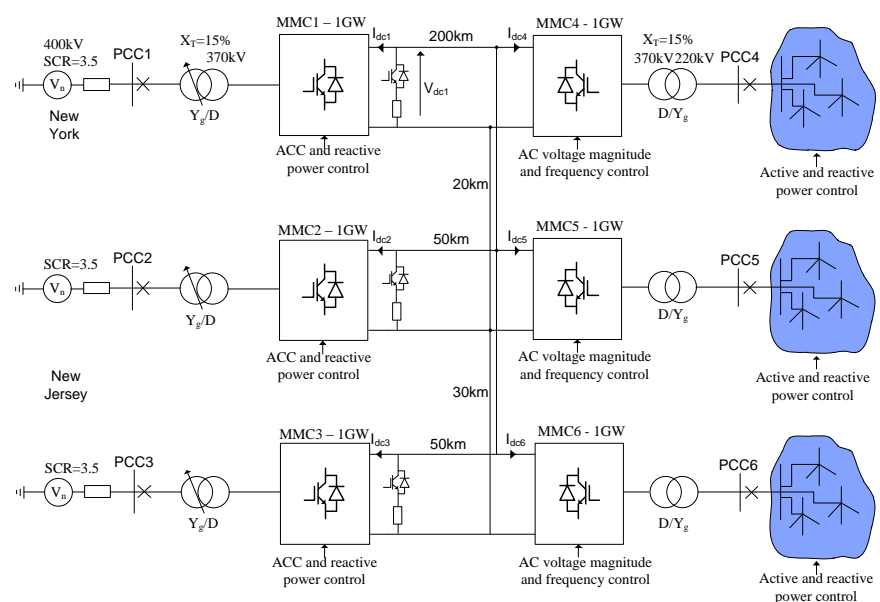

Figure 2: Test model based on the DC configuration for the northern section of the AWC

\section{A. Voltage Source Converter}

One of the key components in a HVDC grid is the VSC. In 2010, the Trans Bay cable project became the first VSCHVDC scheme to use Modular Multi-level Converter (MMC) technology [4]. Today, the main HVDC manufacturers offer a VSC-HVDC solution which is based on multi-level converter technology due to its superior efficiency. It is assumed that the NAWC would employ the Half-Bridge (HB) MMC since it is the only type of MMC which is currently in commercial operation.

There are many techniques for modelling a HB-MMC $[5,6]$. Average Value Models (AVMs) are used to represent the HBMMCs for this work since their accuracy is sufficient for the studies being conducted and they are significantly more computationally efficient than the more detailed models [5]. The MMC-AVM used in this system is implemented and parameterised according to [7].

\section{B. Other components}

The system's HVDC cables are rated for a nominal power of $1 \mathrm{GW}$ at $300 \mathrm{kV}$. The cables are modelled using the frequency dependent phase model which is said to be the most accurate and robust cable model commercially available [8]. In the absence of publicly available data for a commercial HVDC cable model, the estimated geometric and material properties given in [9], with the exception of the shunt conductance, are employed for this work. The shunt conductance is set to $1 \times 10$ ${ }^{10} \mathrm{~S} / \mathrm{m}$ in order to minimise the possibility of passivity violations [10].
Dynamic Braking Systems (DBS) are normally employed on VSC-HVDC schemes used for the connection of windfarms, in order to regulate the DC voltage by dissipating excess wind energy [11]. The DBSs used is in this system employ the two threshold control strategy and are designed to limit the maximum DC voltage to 1.1p.u.

The windfarms are modelled as a three phase voltage source connected to a $33 \mathrm{kV} / 220 \mathrm{kV}$ transformer. The source is controlled using a dq controller to inject active power into the offshore MMCs. The wind turbine, generator and back-toback converter are represented by an approximation of their dominant electrical dynamics, i.e. as a first order power transfer function. The time constant for a large commercial wind turbine is expected to be about $15 \mathrm{~s}$, however such a large time constant would require lengthy simulation times and for illustration it is therefore reduced to $0.15 \mathrm{~s}$ for this model.

\section{Control Layers}

\section{A. Power Flow Solver}

In order to calculate the DC node voltages for the given target DC node powers, one DC node voltage must be known. This node is typically referred to as the DC slack bus. The objective of the PFS is to determine the node power for the slack bus and the node voltages for the other nodes.

By assuming that the cables' shunt conductance can be lumped together and split equally between the ends of each cable, the node powers for a system with $\mathrm{n}$ nodes can be calculated using equation (1), where ". $x$ " denotes elementwise multiplication.

$$
\left[P_{i}\right]=\left[V_{i}\right] \times\left(\left[Y_{i j}\right]\left[V_{j}\right]+\left[V_{i}\right] \times\left[Y_{\text {shunti }}\right]\right)
$$

The matrices for the node powers, $\left[\mathrm{P}_{\mathrm{i}}\right]$, node voltages, $\left[\mathrm{V}_{\mathrm{i}}\right]$ and $\left[\mathrm{V}_{\mathrm{j}}\right]$, series admittances, $\left[\mathrm{Y}_{\mathrm{ij}}\right]$, and shunt admittances $\left[\mathrm{Y}_{\text {shunti }}\right]$ are given by equations (2) and (3).

$$
\left[P_{i}\right]=\left[\begin{array}{c}
P_{1} \\
P_{2} \\
\vdots \\
P_{n}
\end{array}\right] \quad\left[V_{i}\right]=\left[\begin{array}{c}
V_{1} \\
V_{2} \\
\vdots \\
V_{n}
\end{array}\right] \quad\left[V_{j}\right]=\left[\begin{array}{c}
V_{1} \\
V_{2} \\
\vdots \\
V_{n}
\end{array}\right]
$$

$$
\left[Y_{i j}\right]=\left[\begin{array}{cccc}
Y_{11} & Y_{12} & \cdots & Y_{1 n} \\
Y_{21} & Y_{22} & \cdots & Y_{2 n} \\
\vdots & \vdots & \ddots & \vdots \\
Y_{n 1} & Y_{n 2} & \cdots & Y_{n n}
\end{array}\right] ;\left[Y_{\text {shunti }}\right]=\left[\begin{array}{c}
Y_{\text {shunt } 1} \\
Y_{\text {shunt } 2} \\
\vdots \\
Y_{\text {shunt }}
\end{array}\right]
$$

Equation (1) can be solved using the widely used Newton Raphson (NR) method [12, 13]. The NR method is an iterative solution which requires an initial estimate of the node voltages in order to calculate the injected power at each node. The calculated injected powers at each node are then 
compared with the target node powers in order to calculate the error. If the error is within the required tolerance then no further calculations are required. However, if the error is outside the required tolerance then it is used to calculate the change in the node voltages for the next iteration, as described by equation (4) where $[\mathrm{J}]$ is the Jacobian matrix.

$$
\left[V_{\text {new }}\right]=\left[V_{\text {old }}\right]+[\Delta V]=\left[V_{\text {old }}\right]+\operatorname{inv}([\mathrm{J}])[\mathrm{Err}]
$$

A PFS has been developed in MATLAB with a PSCAD interface for the NAWC model. The key steps for the PFS are shown in the flow chart presented in Figure 3. The user enters the target voltage for the DC slack bus (MMC1) and the target DC powers for the other two onshore converters (MMC2 and MMC3). The "target" DC powers at the offshore nodes are measured since the system operator is unable to directly control wind power. If the DC power orders are likely to overload MMC1, error code 1 is passed to PSCAD, which informs the user that the target power orders for $\mathrm{MMC} 2 / 3$ must be modified. Providing that this is not the case, the PFS will calculate the nodal powers in an iterative fashion until they are within their error tolerance. The PFS then checks that the nodal DC powers, DC voltages and cable currents are within their specified limits before issuing new DC voltage and power orders in PSCAD. If any of the DC limits have been violated, the PFS will not issue new DC voltage orders and will instead issue the appropriate error code to indicate to the user which violation has occurred.

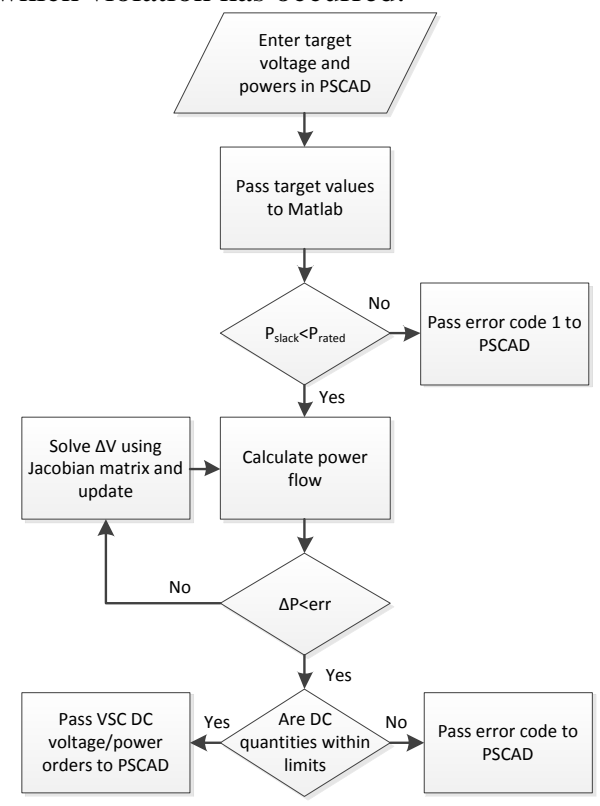

Figure 3: Simplified flowchart for the PFS Algorithm

\section{B. VSC Controls}

A review of MTDC control methods is given in [14]. Generally speaking, these methods can be categorised as centralised DC slack bus, voltage margin control, droop control or a combination of the aforementioned control methods. Unlike DC slack bus and voltage margin control, droop control enables more than one converter to regulate the DC voltage simultaneously and therefore the burden of continuously balancing the system's power flow is not placed upon a single converter. There are many types of droop controller, however they all work on the principle of modifying the converter's active power flow in order to regulate the DC voltage in accordance to their droop characteristic. The gradient of the droop slope determines the converter's response to a change in the DC voltage/current. The converter operates in current limit mode when the DC voltage thresholds are reached.

The droop controller used for this work is referred to as the Autonomous Converter Control (ACC) which was originally proposed by Alstom Grid [1]. The basic implementation of the ACC and the generic VSC control system which is used for this work is shown in Figure 4 and Figure 5.

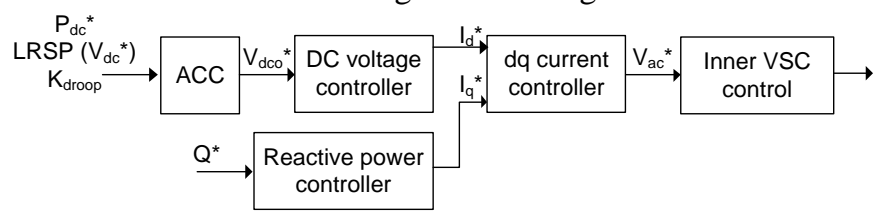

Figure 4: Basic VSC control structure for ACC

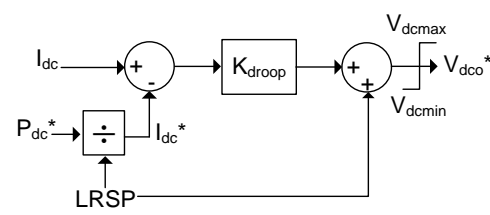

Figure 5: Basic ACC implementation

The controller receives the DC power order, the Load Reference Set-Point (LRSP) and the droop gain from the PFS. It should be noted that the LRSP is the same as the target DC voltage. The term LRSP is used in this paper as it is in keeping with the original literature on the ACC [1]. At steady-state, $\mathrm{I}_{\mathrm{dc}}$ will be equal to $\mathrm{I}_{\mathrm{dc}}{ }^{*}$ providing that the PFS is accurate, and hence the voltage order sent to the DC voltage controller, $\mathrm{V}_{\mathrm{dco}}{ }^{*}$, is equal to the LRSP. However, during transients, $\mathrm{V}_{\mathrm{dco}} *$ varies in accordance to the droop characteristic $\left(\left(\mathrm{I}_{\mathrm{dc}}-\mathrm{I}_{\mathrm{dc}} *\right) \mathrm{K}_{\mathrm{droop}}\right)$.

Feedback PI controllers are used to generate the d-axis and qaxis current orders required to obtain the target DC voltage and reactive power respectively. The current controller is a fast feedback dq controller, which produces a voltage reference for the VSC based upon the current set-point from the outer feedback controller [10]. The inner VSC controls are not modelled since AVMs are used to represent the VSCs.

The AC voltage magnitude and frequency for the offshore networks is set by controlling the d-axis voltage without an inner current loop and by using a voltage controlled oscillator to set the angle based on the frequency set-point for the offshore network.

\section{Operating Frame}

The operating frame of the system defines, amongst other parameters, the DC voltage and DC current limits in the system at steady-state and for transient events. An example of the DC operating frame limits is given in Table 1. 


\begin{tabular}{|c|c|c|c|}
\hline Parameter & Nominal & $\begin{array}{c}\text { Dynamic } \\
\text { Level 1 }\end{array}$ & $\begin{array}{c}\text { Dynamic } \\
\text { Level 2 }\end{array}$ \\
\hline Upper DC voltage limit (p.u.) & 1 & 1.02 & 1.05 \\
\hline Lower DC voltage limit (p.u.) & 0.97 & 0.95 & 0.85 \\
\hline Maximum cable current (p.u.) & 1.03 & 1.05 & 1.4 \\
\hline
\end{tabular}

Table 1: Example operating frame limits

During normal operation, it is the responsibility of the PFS to ensure that the nominal operating frame is not breached. The lower nominal DC voltage limit (e.g. 0.97p.u.) is set to give the PFS a suitably workable DC voltage range while minimising system losses and the maximum nominal DC current. For a transient event (e.g. loss of a converter), the DC voltage and currents will change rapidly and then settle at a new stable operating point. During the transient, the DC voltage and currents should not typically exceed the Dynamic Level 2 (DL2) operating limits and the new operating point should be within the Dynamic Level 1 (DL1) operating frame.

The system will remain at the post-transient operating point until the PFS is able dispatch a new set of converter orders. The time it takes for the PFS to send a new set of converter orders could be less than $10 \mathrm{~ms}$ for a small system with a high update frequency or more than several hours if the PFS or telecommunications has failed. The possibility of the later scenario occurring is likely to result in the DL1 limits being set within a few per cent of the nominal limits. It is also important to consider the impact the lower DC voltage limit will have on the maximum available AC converter voltages, as this may adversely affect the control of the converters.

For some transient events the DL2 limits will be violated and protective actions are required. For example in the event of a severe fault in the onshore AC system, the onshore converters may not be able to export all of the wind power leading to a violation in the upper DL2 DC voltage limit. For this work, once this limit has been violated the DBSs are activated to regain control over the DC voltage.

Figure 6 gives a more detailed view of the HVDC grid control architecture employed and the control layers which have the greatest impact on the different operating frame limits.

In order to ensure that the DL1 operating frame will not be violated, the DC voltage and current values must be known for the new operating point following the worst case transient event. As part of this work, guidelines were developed to help determine the scenario(s) which are likely to result in a DL1 violation. For example, the following could be used for selecting the scenario(s) which are likely to result in the highest short-term DC voltage:

1. Only one converter is able to regulate the DC voltage.

2. The last converter regulating the DC voltage has the steepest voltage/current droop characteristic.

3. Before the transient event, the converter regulating the DC voltage is importing maximum power from the AC system at the upper limit of the nominal DC voltage.

4. The transient event resulting in the greatest surplus of active power in the DC grid.

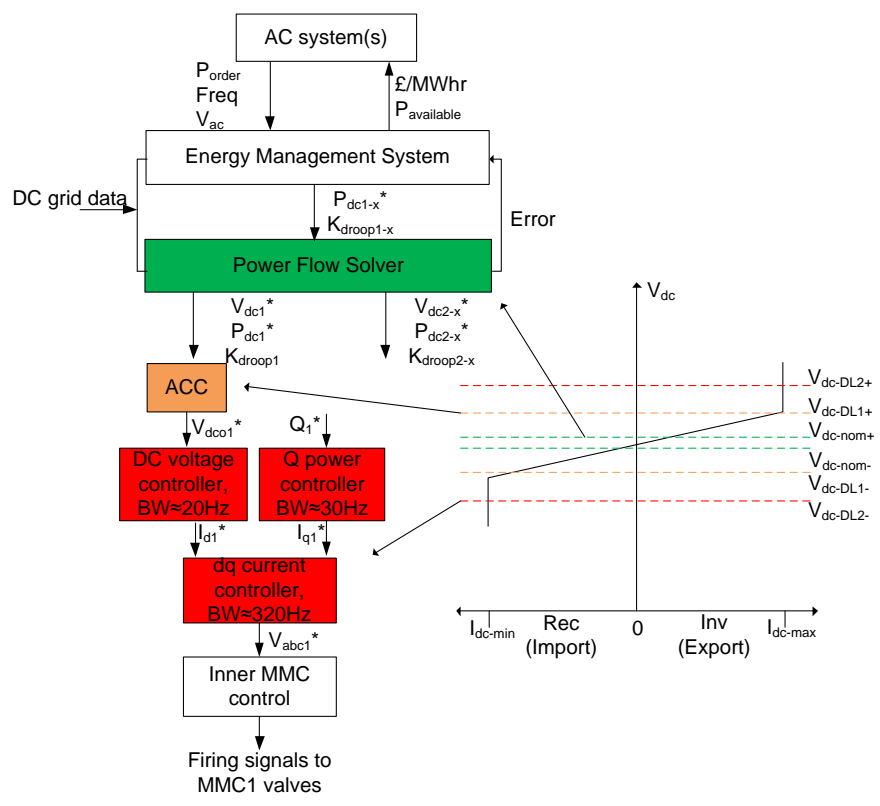

Figure 6: Example HVDC control architecture and the influence of control layers on the operating frame limits

Once the worst case scenarios have been identified, the new voltage and current values (after the transient event) can be determined. Since only one converter is regulating the DC voltage for many of the worst case scenarios, the approximate power flow after the transient event is known. This enables a simple droop equation to be used to calculate the DC voltage value for the converter which is regulating the DC voltage. This value can then be used by the PFS to determine the DC voltage at the other nodes. For scenarios where the approximate power flow is not known a more accurate generalised power flow solver or linearized equations can be employed $[13,15]$.

Large droop gains for ACC (steep droop) increase the likelihood of operating frame violations, however small gains reduce the ability of the ACC to influence converter power sharing for transient events. When tuning the ACCs in this work a starting droop gain of $10(\mathrm{kV} / \mathrm{kA})$ is used. This gain is then reduced in an iterative fashion until there are no operating frame violations for the selected worst case scenario.

\section{Simulation Results}

A number of case studies were simulated, the results of which are presented in this section. Unless stated otherwise, the target DC voltage for VSC1 is $594 \mathrm{kV}$ and the droop gain for all ACCs is $3.5(\mathrm{kV} / \mathrm{kA})$.

\section{A. Steady-state error}

The active power injected into the DC system by windfarm 1, $\mathrm{P}_{\mathrm{dc} 4}$, windfarm $2, \quad \mathrm{P}_{\mathrm{dc} 5}$, and windfarm $3, \quad \mathrm{P}_{\mathrm{dc} 6}$, are 
approximately 500MW, 250MW and 600MW respectively. The target DC power orders for VSC2, $\mathrm{P}_{\mathrm{dc} 2}$, and VSC $3, \mathrm{P}_{\mathrm{dc} 3}$, are set to $600 \mathrm{MW}$ and $400 \mathrm{MW}$ respectively. The system's DC power flow accuracy is given in Table 2. It should be noted that only the DC power values for VSC2 and VSC3 are included in Table 2, as these are the only values which the user is able to control. This result shows that accurate control of the steady-state power flow can be achieved; however such a high degree of accuracy should not be expected in a practical system due to factors such as measurement errors. Hence, using a very small error tolerance parameter in the PFS will not necessarily improve the power flow accuracy.

\begin{tabular}{|c|c|c|c|c|}
\hline Node & $\begin{array}{c}\text { Target } \\
\text { (MW) }\end{array}$ & $\begin{array}{c}\text { Simulated } \\
(\mathbf{M W})\end{array}$ & $\begin{array}{c}\text { Error } \\
(\mathbf{M W})\end{array}$ & $\begin{array}{c}\text { Error } \\
(\%)\end{array}$ \\
\hline Pdc2 & 600 & 600.277 & 0.277 & 0.046 \\
\hline Pdc3 & 400 & 400.146 & 0.146 & 0.037 \\
\hline
\end{tabular}

Table 2: Power flow accuracy

\section{B. Droop control using same droop constants}

The initial DC power and voltage orders to the converters are set to the same values as in the previous scenario. The droop gains for all of the converters employing $\operatorname{ACC}(1,2 \& 3)$ are set to 3.5 and the PFS is disabled. At $5 \mathrm{~s}$, the power injected by windfarm 2 increases from $250 \mathrm{MW}$ to $750 \mathrm{MW}$. Figure 7 shows that all of the converters operating in ACC regulate the DC voltage by sharing the DC power increase. The onshore converters share the increase in wind power according to the system's configuration, droop gain, initial operating conditions and the point in the system where the wind power is increased.

\section{Droop control using different droop constants}

This scenario is the same as the previous scenario, except that the droop constant for VSC3 is reduced to 1.5. Figure 8 shows that VSC3 participates more actively in the regulation of the DC voltage as a result of reducing the droop constant.

\section{Droop control using same droop constants with PFS}

This scenario is the same as the scenario in section B. except that the PFS is enabled with an update frequency of $10 \mathrm{~Hz}$. The PFS automatically adjusts the converter set-points to obtain the target DC power flows for VSC2 and VSC3, as shown in Figure 9. Note that the target DC voltage for VSC 1 is reduced to prevent a nominal DC voltage overvoltage.

\section{E. Disconnection of onshore converter}

The active power injected into the DC system by windfarms 1,2 and 3 are approximately 500MW, 900MW and 600MW respectively. The target DC power orders for VSC2 and VSC3 are set to $1000 \mathrm{MW}$ and $500 \mathrm{MW}$ respectively and the PFS is enabled. At $3 \mathrm{~s}$ the AC circuit breakers for VSC2 are tripped and the system's response is shown in Figure 10. This figure shows that VSC1 and VSC3 respond to the event by rapidly exporting more active power in order to regulate the DC voltage. It should be noted that if VSC1 and VSC3 were unable to export the active power lost by VSC2 then the DC voltage would increase to approximately $630 \mathrm{kV}$, at which point the dynamic braking resistors would be enabled.

\section{F. DL1 operating frame test}

From the guidelines set out in section 5, the following scenario was identified as one of the worst case scenarios which could cause a DL1 violation. In this scenario, the windfarm power is initial set to zero, VSC2 is blocked and VSC1 is importing maximum power $(1 \mathrm{GW})$ at the upper nominal voltage limit $(600 \mathrm{kV})$. For this scenario it is assumed that up to $1400 \mathrm{MW}$ of wind power could be injected into the DC grid before the PFS is able to act. Based on the method outlined in section 5, the droop gain should not be set above $3.5(\mathrm{kV} / \mathrm{kA})$ as this would cause a DL1 violation. At $5 \mathrm{~s}$ the active powers for windfarms 2 and 3 are increased to $400 \mathrm{MW}$ and $1000 \mathrm{MW}$ respectively and the PFS is disabled as shown in Figure 11. VSC3 exports an additional 20MW to its 1000MW limit and then VSC1 must regulate the DC voltage by exporting close to $380 \mathrm{MW}$. The maximum DC voltage for this scenario when using a droop gain of 3.5 was estimated to be $611.3 \mathrm{kV}$, which is close to the simulated value of $611.1 \mathrm{kV}$.

\section{Conclusion}

In this paper, the main layers of the overall HVDC grid control architecture have been described and the key VSC control signals have been defined. A model based on the DC configuration of the northern section of the Atlantic wind connection has been implemented with the main control layers in PSCAD and Matlab. A range of tests have been conducted which show that the control system is able to accurately control DC power flow in steady-state and to maintain grid stability for fast transient events without exceeding the dynamic operating limits.

\section{Acknowledgements}

The authors would like to thank Mr Robert Whitehouse, Dr Wenyuan Wang and Dr Colin Oates for their useful discussions.

This work was supported by the Engineering and Physical Sciences Research Council (EPSRC) through grant EP/H018662/1 - Supergen 'Wind Energy Technologies'.

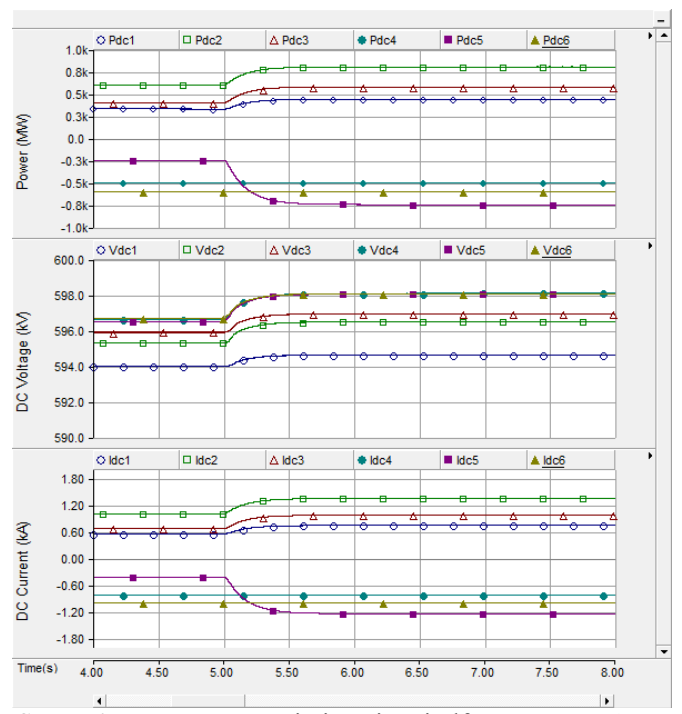

Figure 7: System's response to variations in windfarm power when employing the same droop constant; $\mathrm{x}$-axis is time in seconds 


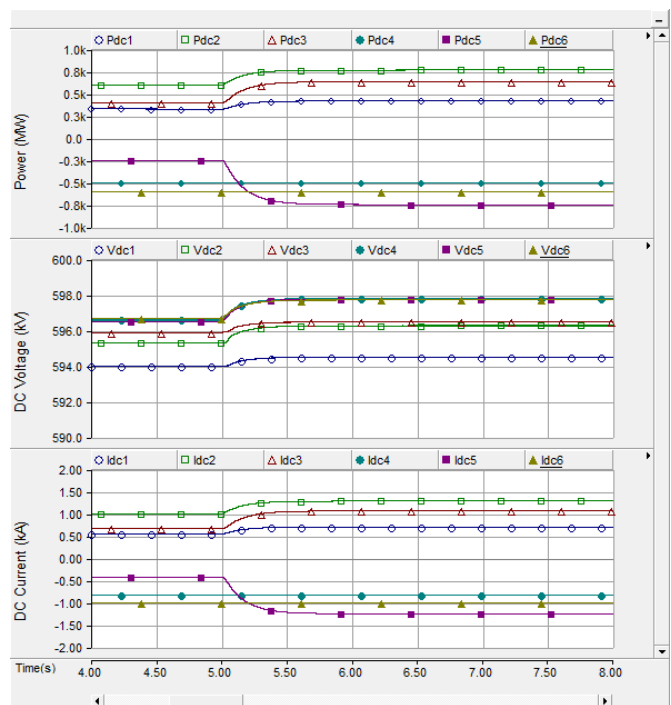

Figure 8: System's response to variations in windfarm power when employing different droop constants

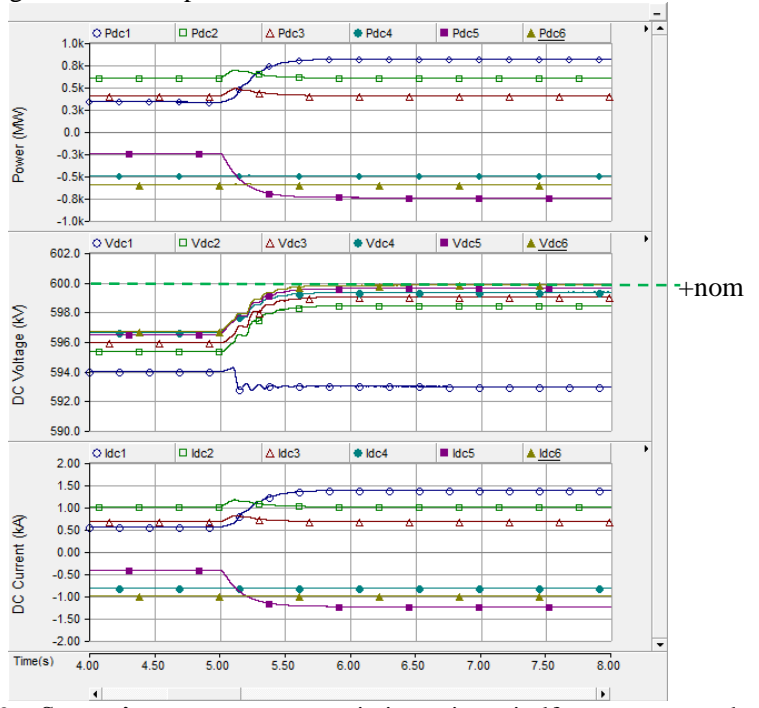

Figure 9: System's response to variations in windfarm power when employing the same droop constant with the PFS engaged using an update frequency of $10 \mathrm{~Hz}$

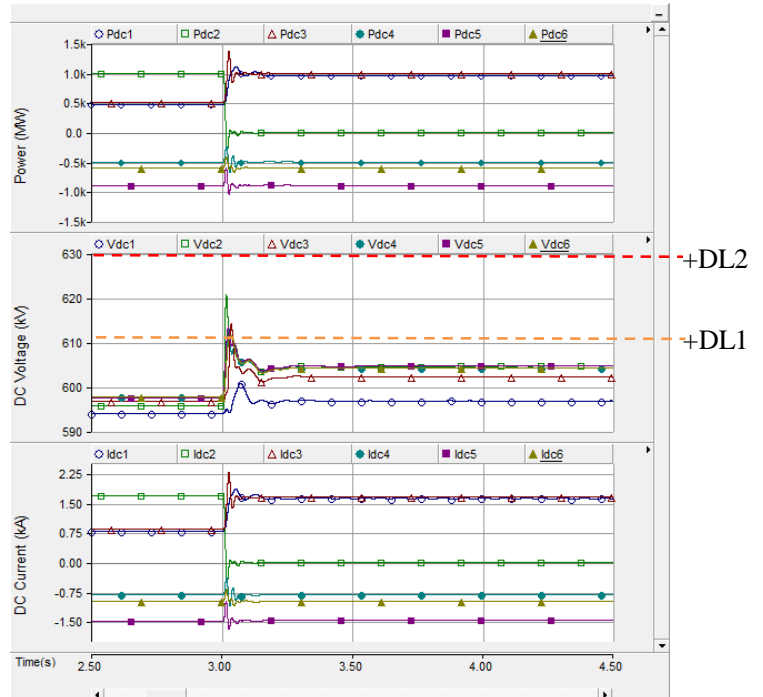

Figure 10: System's response to tripping the AC circuit breakers for VSC 2 at $3 \mathrm{~s}$

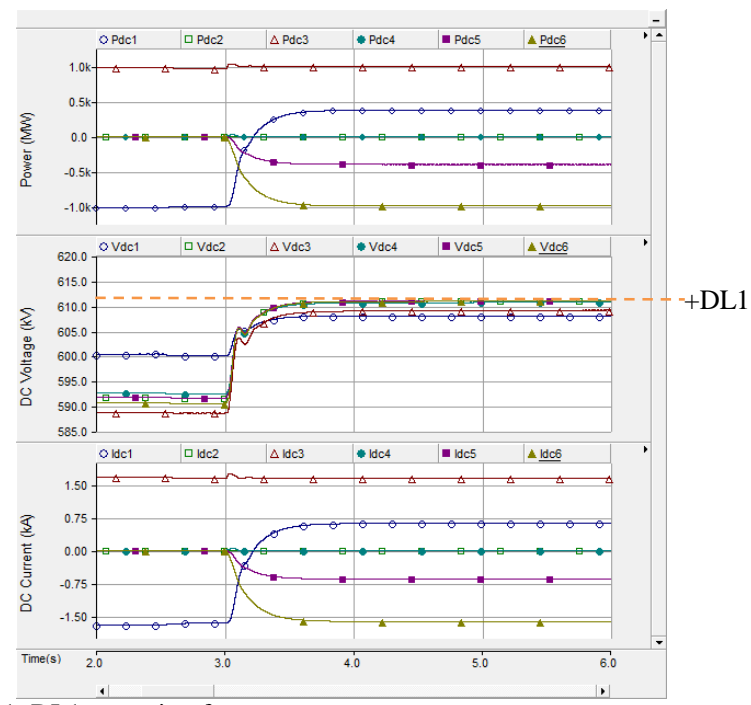

Figure 11: DL1 operating frame test

\section{References}

[1] C. D. Barker and R. Whitehouse, "Autonomous converter control in a multi-terminal HVDC system," in IET AC and DC Power Transmission, 2010.

[2] C. D. Barker and R. S. Whitehouse, "Further developments in autonomous converter control in a multi-terminal HVDC system," in AC and DC Power Transmission (ACDC 2012), 10th IET International Conference on, 2012, pp. 1-6.

[3] The Chertoff Group, "Atlantic Wind ConnectionGrid Resiliency, Its Economic and Security Impacts, and the Implications of AWC," Company Report, 2012.

[4] M. Barnes and A. Beddard, "Voltage Source Converter HVDC Links - The state of the Art and Issues Going Forward," Energy Procedia, pp. 108-122, 2012.

[5] H. Saad, S. Dennetie, J. Mahseredjian, P. Delarue, X. Guillaud, J. Peralta, et al., "Modular Multilevel Converter Models for Electromagnetic Transients," Power Delivery, IEEE Transactions on, vol. 29, pp. 1481-1489, 2014.

[6] A. Beddard, M. Barnes, and R. Preece, "Comparison of Detailed Modeling Techniques for MMC Employed on VSC-HVDC Schemes," Power Delivery, IEEE Transactions on, vol. PP, pp. 111,2014

[7] A. Beddard and M. Barnes, "Average Value Modelling of Modular Multi-level Converters," University of ManchesterInternal Report, 2014.

[8] PSCAD, "PSCAD User's Guide," vol. 4.2.1, 2010

[9] A. Beddard and M. Barnes, "HVDC cable modelling for VSCHVDC applications," in PES General Meeting | Conference \& Exposition, 2014 IEEE, 2014, pp. 1-5.

[10] A. Beddard and M. Barnes, "Modelling of MMC-HVDC Systems - An Overview," Elsevier - Energy Procedia, 2015.

[11] Y. Jiang-Häfner and R. Ottersten, "HVDC with Voltage Source Converters - A Desirable Solution for Connecting Renewable Energies," Large scale integration of wind power into power systems, 2010.

[12] T. M. Haileselassie and K. Uhlen, "Power flow analysis of multiterminal HVDC networks," in PowerTech, 2011 IEEE Trondheim, 2011, pp. 1-6.

[13] W. Wenyuan and M. Barnes, "Power Flow Algorithms for MultiTerminal VSC-HVDC With Droop Control," Power Systems, IEEE Transactions on, vol. 29, pp. 1721-1730, 2014.

W. Wang, M. Barnes, and O. Marjanovic, "Droop control modelling and analysis of multi-terminal VSC-HVDC for offshore wind farms," in AC and DC Power Transmission (ACDC 2012), 10th IET International Conference on, 2012, pp. 1-6.

J. Beerten and R. Belmans, "Analysis of Power Sharing and Voltage Deviations in Droop-Controlled DC Grids," Power Systems, IEEE Transactions on, vol. 28, pp. 4588-4597, 2013. 